\title{
Delays after eating: Effects on transmission of diet preferences and aversions
}

\author{
BENNETT G. GALEF, JR., and DEBORAH J. KENNETT \\ McMaster University, Hamilton, Ontario, Canada
}

\begin{abstract}
Previous studies have demonstrated that a naive rat (an observer), after interacting with a previously fed conspecific (a demonstrator), will exhibit an enhanced preference for the diet its demon. strator ate. Furthermore, observers poisoned after interacting with demonstrators exhibit an aversion to their respective demonstrators' diets. In the present paper, we examined the effects, on transmission of information from demonstrator to observer, of introducing delays between the end of demonstrator feeding and initiation of demonstrator-observer interaction. We found that (1) for at least $4 \mathrm{~h}$ after ingestion, demonstrator rats emitted diet-related cues sufficient to alter observers' subsequent diet preferences, and (2) diet-related cues emitted by demonstrators for 1 to $2 \mathrm{~h}$ after a meal were adequate conditional stimuli for aversion learning by their observers.
\end{abstract}

A naive rat (an observer) can extract information from a recently fed conspecific (a demonstrator) sufficient to permit the observer to identify the particular food its demonstrator has eaten (Galef \& Wigmore, 1983; Posadas-Andrews \& Roper, 1983; Strupp \& Levitsky, 1984). We have studied this type of information transfer between rats as a laboratory analogue of a naturally occurring situation in which a foraging rat ingests a food at some distance from its burrow, returns to its burrow, and interacts with a burrowmate that subsequently leaves the burrow and selects a food to eat. Our previous results (Galef, 1983; Galef \& Wigmore, 1983) demonstrate that successful foragers can communicate information to their burrowmates, affecting the latters' future foraging activities.

In the experiments reported below, we examined the effects on information transmission from demonstrators to observers of introducing temporal delays between ingestion by demonstrators and their interaction with observers.

\section{EXPERIMENT 1}

In our previous studies of transfer of information from demonstrator to observer concerning distant diets (Galef $\&$ Wigmore, 1983), we both (1) permitted observer and demonstrator to interact immediately after the demonstrator had eaten some diet and (2) gave each observer the

The research reported here was supported by grants from the Natural Sciences and Engineering Research Council of Canada and McMaster University Research Board. We thank Sandra Vegeris, Denise Stevens, Tania Massing, and Roy Kaufmann for their assistance in the collection and analysis of data. Harvey Weingarten, Mertice Clark, and Matthew Beck provided useful discussions of earlier drafts of the manuscript. D. J. Kennett is now at Brock University, St. Catherines, Ontario. Requests for reprints should be sent to Bennett G. Galef, Jr., Department of Psychology, McMaster University, Hamilton, Ontario, Canada L8S $4 \mathrm{~K} 1$. opportunity to choose between diets immediately following interaction with its demonstrator. In natural circumstances, a forager must expend time in returning from a feeding site to its home burrow, and individuals leaving the home burrow to forage must expend further time in reaching a feeding site. If the capacity of rats to acquire information from conspecifics concerning a food eaten at a distance from the burrow facilitates feeding in natural circumstances, transmission must occur even in the face of delays (1) between a successful forager's ingestion of a food and its return to the burrow, and (2) between the interaction of a successful forager with other rats and the latters' arrival at a potential feeding site. Previous research (Galef, 1983) has demonstrated that once an observer and demonstrator have interacted, the observer can use information acquired from a demonstrator as much as $12 \mathrm{~h}$ later in selecting a diet. In the present experiment, we wanted to determine how long after a demonstrator had eaten it would continue to emit a diet-identifying signal sufficient to influence diet selection by its observer.

\section{Method}

Subjects. Sixty-four experimentally naive 42-day-old Long-Evans rats born in the McMaster colony to breeding stock acquired from Blue Spruce Farms (Altamont, NY) served as observers. An additional 64 92-day-old rats served as demonstrators. These demonstrators had been observers in previous studies.

Apparatus. During the experiment, all subjects were housed and tested in same-sex demonstrator-observer pairs in $42.5 \times 24 \times$ $17.5 \mathrm{~cm}$ wire-mesh hanging cages (Wahmann Co., Baltimore, MD). Each cage was divided into two equal parts by a .5 -in. $(1.25 \mathrm{~cm})$ hardware-cloth screen attached at the midpoint of each $42.5-\mathrm{cm}$ side.

Procedure. Treatment of subjects during the experiment was as follows (see Figure 1): Step 1-Demonstrator and observer were first maintained together with ad-lib access to Purina Laboratory Rodent Chow pellets for a 2-day period of familiarization with both apparatus and pairmate. Step 2-Each demonstrator was moved to the opposite side of the hardware-cloth partition from its observer and food-deprived for $24 \mathrm{~h}$ to insure that it fed when given the opportunity to do so. Step 3-Rat chow was removed from the observer's side of the apparatus (in preparation for testing), and the 


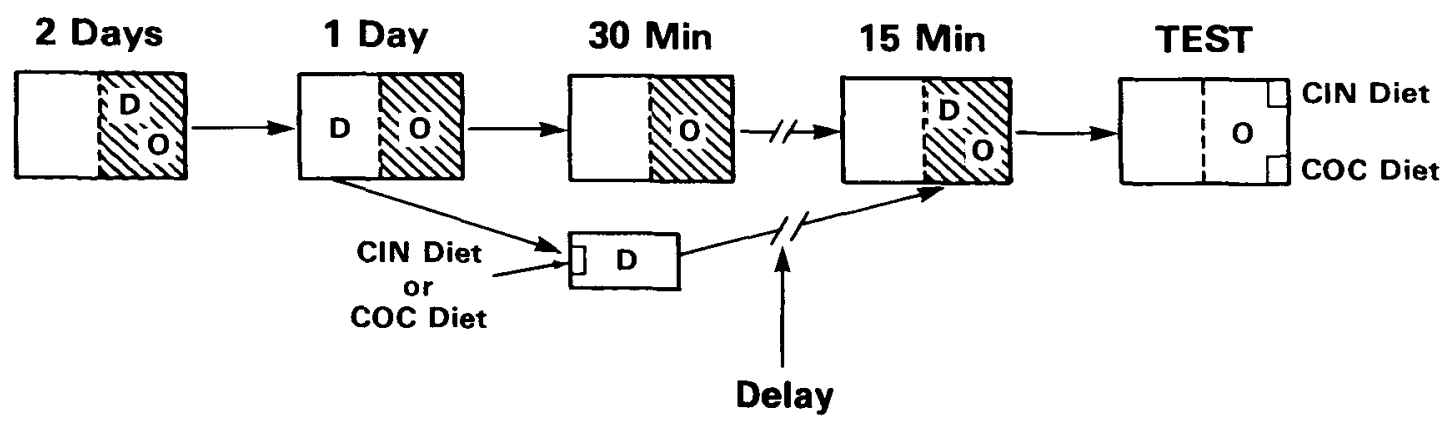

\section{Step 1 \\ Step 2 \\ Step 3 \\ Step 4 \\ Step 5}

Figure 1. Schematic diagram of the procedure of Experiment 1. $(O=$ observer; $D=$ demonstrator. Hatching indicates pellets of Purina Laboratory Rodent Chow present in cage.)

demonstrator was moved to an enclosure in a separate room and allowed to feed for $30 \mathrm{~min}$ on either powdered Purina Laboratory Rodent Chow adulterated $2 \%$ by weight with Hershey's cocoa (Coc diet) or powdered Purina Laboratory Rodent Chow adulterated 1\% by weight with McCormick's pure ground cinnamon (Cin diet). Step 4-After a delay of $0,2,4$, or $6 \mathrm{~h}$, each demonstrator was returned to its observer's side of the cage, and the demonstrator and observer were allowed to interact for $15 \mathrm{~min}$. Step 5-The demonstrators were removed from the experiment, and each observer was offered, for $18 \mathrm{~h}$, two weighed food cups, one containing the Cin diet and the other containing the Coc diet.

\section{Results and Discussion}

The results of Experiment 1 are presented in Figure 2, which shows the mean amount of Coc diet, as a percentage of total amount eaten, ingested by observers whose demonstrators had eaten either the Coc diet or the Cin diet during Step 4 of the experiment. As can be seen in the figure, and as statistical tests confirmed (MannWhitney $U$ tests, see Figure 2 for $U$ and p values), observers that interacted with demonstrators 0,2 , or $4 \mathrm{~h}$ after those demonstrators had eaten exhibited an enhanced preference for their respective demonstrators' diets. The observers that interacted with demonstrators fed $6 \mathrm{~h}$ earlier did not show a significant tendency to select their respective demonstrators' diets. The implication of these results is that for at least $4 \mathrm{~h}$ after eating either the Cin diet or the Coc diet a demonstrator rat emits cues sufficient to permit recognition of that diet by conspecifics. Because rats in natural circumstances are likely to return to their burrows within $4 \mathrm{~h}$ of feeding (Chitty, 1954), the mechan-

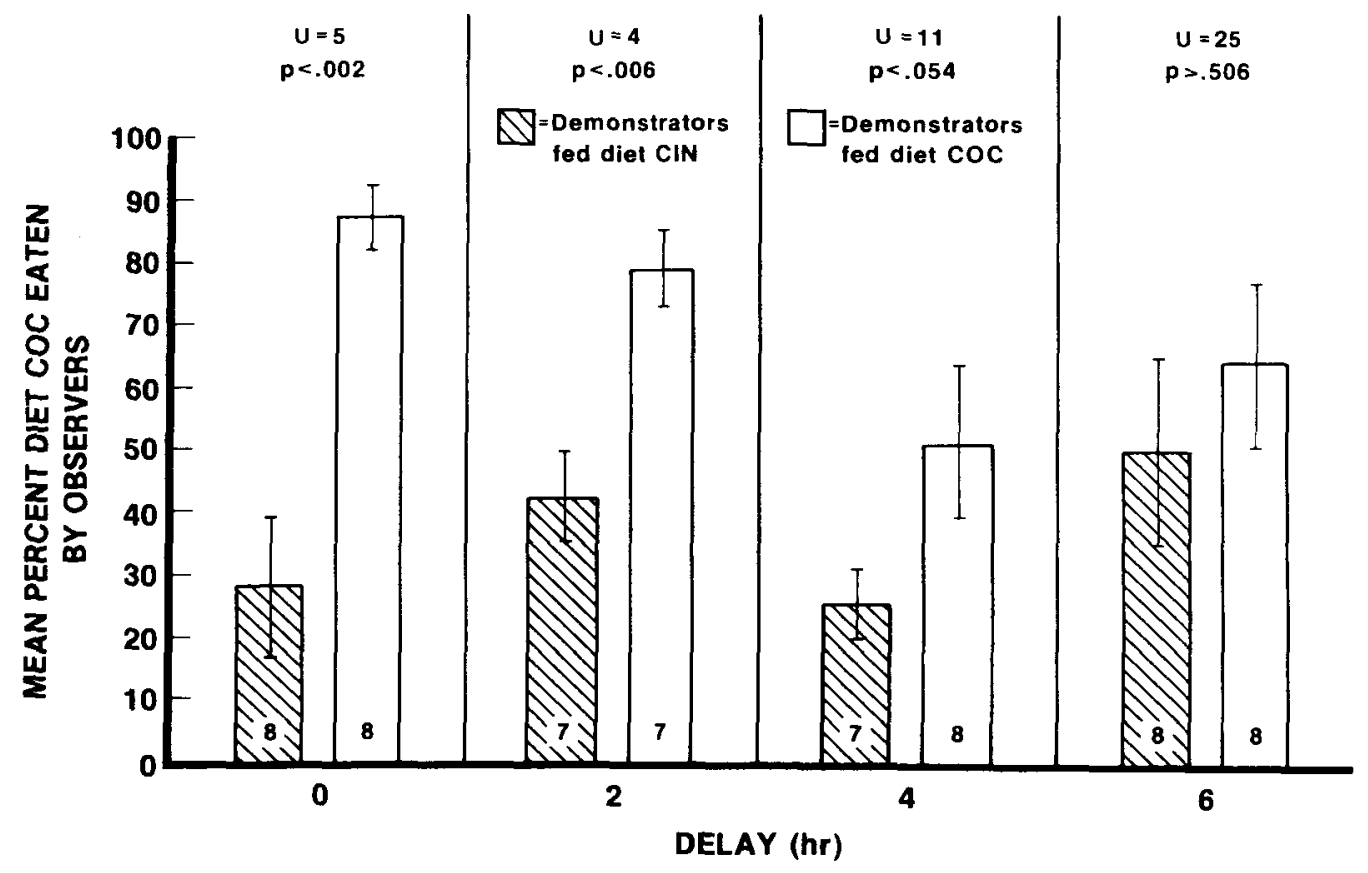

Figure 2. Mean amount of Coc diet ingested by observers as a percentage of total amount eaten. (Bars indicate $\pm 1 \mathrm{SE}$; digits in histograms $=$ Ns.) 
ism for transmission of diet preference under investigation here appears to be one that would be useful in natural settings.

\section{EXPERIMENT 2}

Previous studies in our laboratory (Galef, Wigmore, \& Kennett, 1983) have shown that the cues emitted by a demonstrator rat immediately after it has eaten a diet are an adequate conditional stimulus for an observer to learn an aversion to its demonstrator's diet. In the present experiment, we examined the adequacy of cues emitted by a demonstrator some hours after it had eaten a diet to serve as a $\mathrm{CS}$ in aversion learning by observers.

\section{Method}

Subjects. Ninety-six 42-day-old experimentally naive Long-Evans rats from the McMaster colony served as observers. An equal number of 60- to 80-day-old rats from the same source served as demonstrators.

Apparatus. The apparatus was that used in Experiment 1.

Procedure. The procedure was the same as that employed in Experiment 1 (see Figure 1) except (1) in the delays imposed between the feeding of demonstrators (Step 3) and the interaction of demonstrators and observers (Step 4), and (2) in the treatment of observers following interaction with demonstrators.

In the present experiment, two groups of observers (24 subjects/group) interacted with their respective demonstrators immediately after their demonstrators had been fed (0-delay groups), one group of observers ( 24 subjects) interacted with their demonstrators $1 \mathrm{~h}$ after their demonstrators had been fed (1-h-delay group), and one group of observers interacted with their demonstrators $2 \mathrm{~h}$ after their demonstrators had been fed (2-h-delay group).

Immediately following each observer's 15 -min period of interaction with its demonstrator, it received an intraperitoneal injection of $1 \%$ body weight of solution. Subjects in one of the 0 -delay groups and both the 1-h- and 2-h-delay groups were injected with
$1 \%$ body weight of $2 \%(\mathrm{w} / \mathrm{v}) \mathrm{LiCl}$ solution. Subjects in the remaining 0-delay group were injected with an equivalent volume of isotonic saline solution. Fifteen minutes after the injection, each observer was offered a choice between the Cin diet and the Coc diet for $18 \mathrm{~h}$.

Data analysis. Although comparison of the mean percentage of the Coc diet eaten by observers whose demonstrators had eaten the Coc or Cin diet is useful in determining demonstrator effects on observer diet preference within a delay condition, this measure is not suitable for comparisons between delay conditions. To compare the behavior of subjects in different delay conditions, we calculated, for each subject, a descriptive statistic we call "percentage demonstrators' diet eaten." It is the percentage of Coc diet eaten by observers whose demonstrators had eaten the Coc diet or the percentage Cin diet eaten by observers whose demonstrators had eaten the Cin diet. The greater the degree of matching of the diet preference of observers to the diet eaten by their respective demonstrators, the larger the mean percentage the demonstrators' diet eaten by those observers.

\section{Results and Discussion}

The main results of Experiment 2 are presented in Figure 3. The left-hand panel of Figure 3 shows the mean amount of Coc diet, as a percentage of total amount eaten, ingested in the four treatment conditions by observers whose demonstrators had eaten the Coc or Cin diet during Step 3 of the experiment. The right-hand panel presents the mean percentage demonstrators' diet eaten by observers in the same four groups.

As can be seen in the left-hand panel of Figure 3, observers in the saline/0-delay group whose demonstrators had eaten the Coc diet ate significantly more of the Coc diet than did observers whose demonstrators had eaten the Cin diet. On the other hand, observers in the $\mathrm{LiCl} / 0$ delay and $\mathrm{LiCl} / 1$-h-delay groups whose demonstrators had eaten the $\mathrm{Coc}$ diet ate significantly less of the Coc diet than did those observers whose demonstrators had eaten

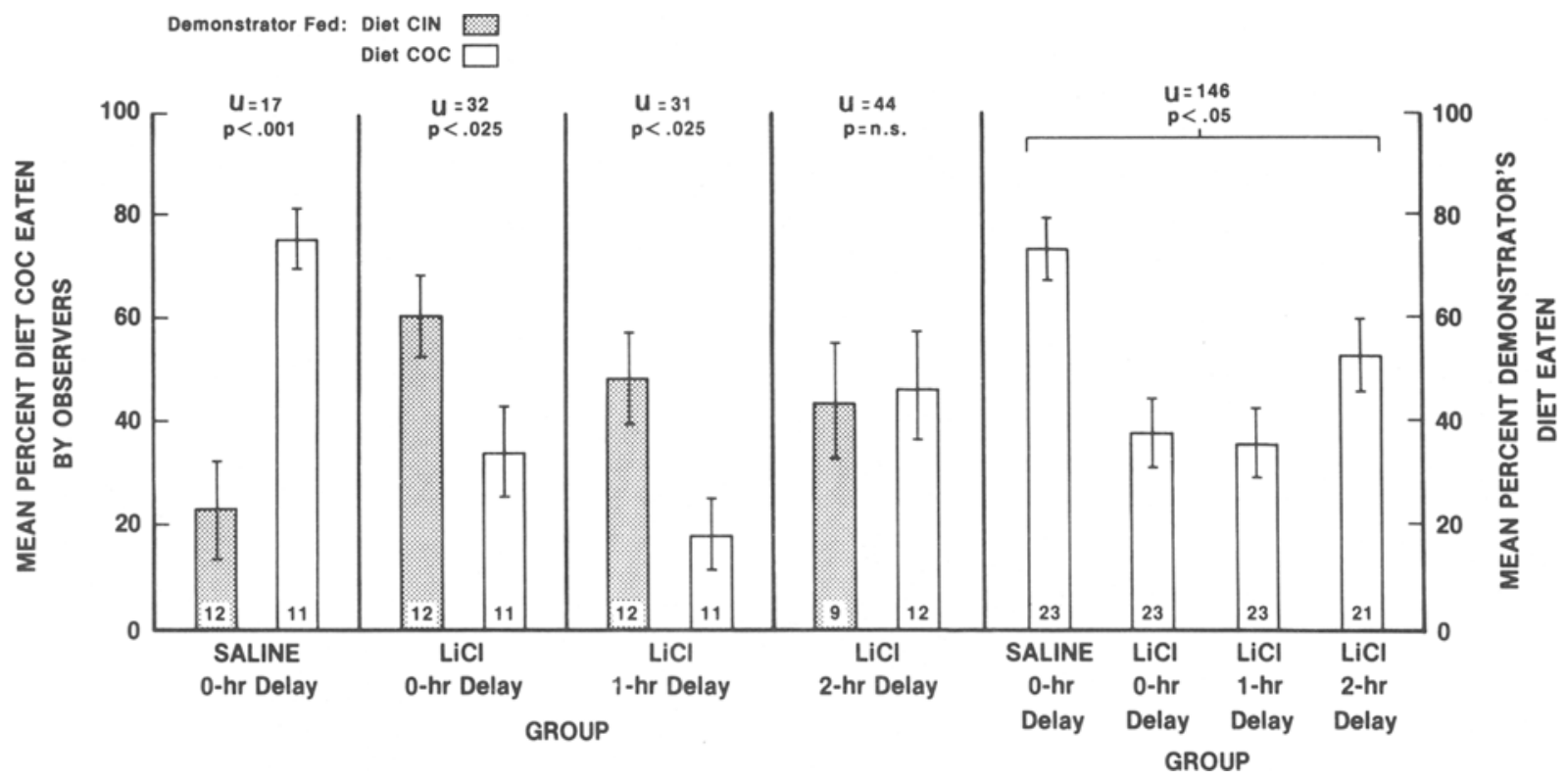

Figure 3. Left panel: Mean amount of Doc diet ingested by observers as a percentage of total intake. Right panel: Mean percentage of demonstrators' diet eaten by observers. See Method of Experiment 3 for explanation of groups and data analyses. (Bars indicate $\pm 1 \mathrm{SE}$; digits in histograms $=$ Ns.) 
the Cin diet. As can be seen in the right-hand panel of Figure 3, subjects in both the $\mathrm{LiCl} / 0$-delay and the $\mathrm{LiCl} / 1$ h-delay groups (those poisoned following interaction with a demonstrator) exhibited an aversion to their respective demonstrators' diets. Observers in the $\mathrm{LiCl} / 2$-h-delay condition did not exhibit either a preference for or aversion to their demonstrators' diets (left-hand panel of Figure 3). Observers in this condition did, however, exhibit, relative to observers in the saline/0-delay condition, a significantly reduced tendency to select their demonstrators' diets for ingestion (right-hand panel of Figure 3). We interpret these data as suggesting weak aversion learning by observers in the $\mathrm{LiCl} / 2$-h-delay condition. Taken together, the results of the present experiment suggest that residual cues sufficient to support aversion learning in observers are emitted by demonstrators for 1 and, perhaps, $2 \mathrm{~h}$ following ingestion of a diet.

A comparison of the results of Experiments 1 and 2 reveals that the diet-identifying cues emitted by demonstrator rats at various times after termination of feeding are differentially effective as CSs in aversion learning and as inducers of preference for demonstrators' diets. Four hours after eating, demonstrators in Experiment 1 were still emitting diet-identifying cues adequate to enhance their respective observers' preferences for their respective diets; the same diet-identifying cues emitted by demonstrators could serve as CSs for observers in an aversion learning situation for only 1-2 $\mathrm{h}$ after demonstrator feeding. Unfortunately, our data are inadequate to determine the causes of this difference in the apparent time course of the emission of diet-identifying cues by demonstrators as a function of the dependent measure employed. However, it is probably relevant to note that: (1) strength of aversion learning is positively related to CS strength
(Barker, 1976), and (2) the learning of aversions to olfactory cues by rats is, in general, weak (Hankins, Garcia, \& Rusiniak, 1973). Learning by observers of aversions to demonstrator-emitted diet-identifying CSs may therefore be restricted to the relatively brief period when olfactory diet-identifying cues emitted by demonstrators are particularly strong.

\section{EXPERIMENT 3}

Both the specificity of observers' aversions to their respective demonstrators' diets in a choice situation and the differential effects of delays of varying duration on the strength of observers' aversions to demonstrators' diets mitigate against interpretation of the outcome of Experiment 2 as resulting from unconditioned effects of toxicosis on observer diet preference. However, Experiment 2 contained no explicit control for pseudoconditioning effects. The present experiment was, therefore, undertaken to replicate the main positive finding of Experiment 2, the adequacy of residual diet-identifying cues emitted by a demonstrator 1-h after ingestion of a diet to support aversion learning in observers while controlling for the unconditioned effects of toxicosis induction.

\section{Method}

Subjects. Forty-eight 42-day-old experimentally naive LongEvans rats from the McMaster colony served as observers, and an additional 48 60-90-day-old rats served as demonstrators.

Procedure. Observers in the experimental group $(n=24)$ were treated identically to those in the $\mathrm{LiCl} 1$-h-delay group of Experiment 2 . Observers $(n=24)$ in the control group were treated identically to those in the experimental group, except that instead of injecting observers in the control group with $1 \%$ of body weight of $2 \%(\mathrm{w} / \mathrm{v}) \mathrm{LiCl}$ solution immediately following interaction with

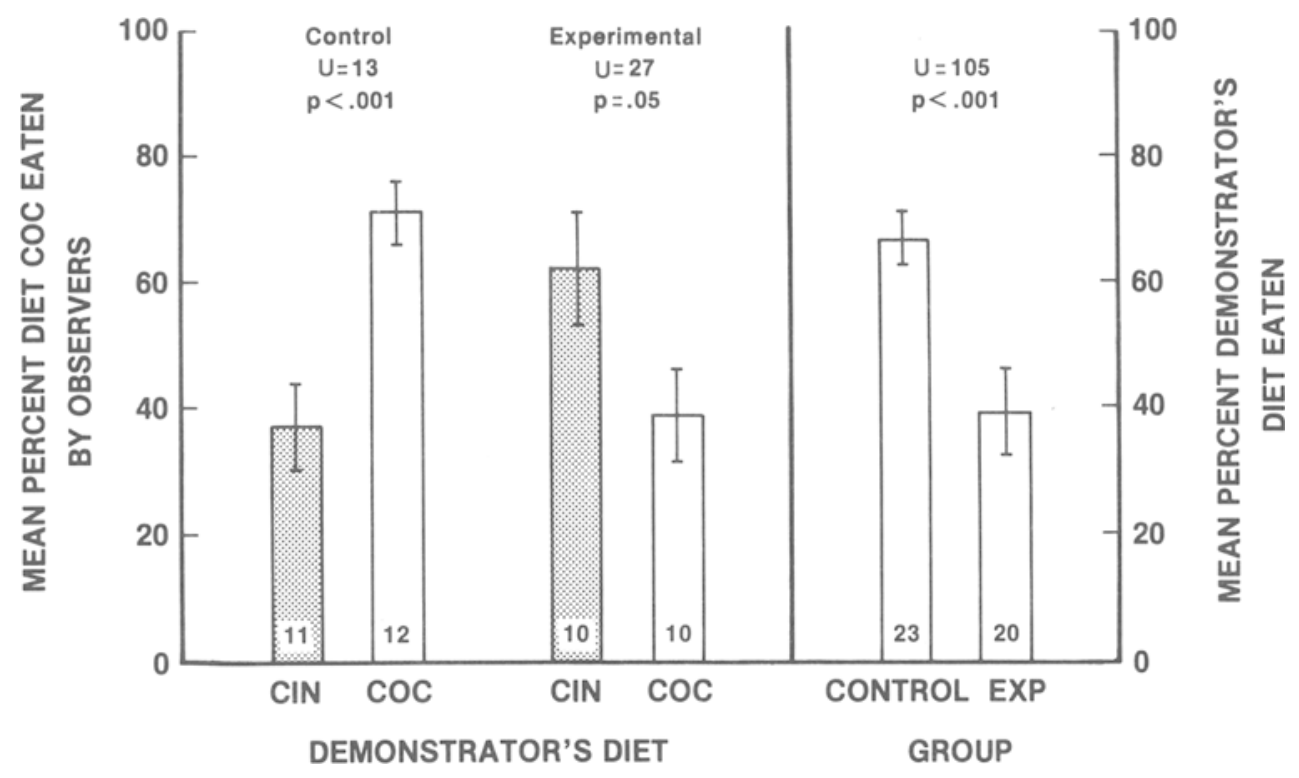

Figure 4. Left panel: Mean amount of Coc diet ingested by observers as a percentage of total intake. Right panel: Mean percentage of demonstrators' diet eaten by observers. See Method of Experiment 4 for explanation of groups, and see Method of Experiment 2 for explanation of data anlyses. (Bars indicate \pm 1 SE; digits in histograms $=$ Ns.) 
their demonstrators, we injected them with equivalent volumes of $\mathrm{LiCl}$ solution $4 \mathrm{~h}$ prior to their interaction with the demonstrators.

\section{Results and Discussion}

The main results of Experiment 3 are presented in Figure 4. The left panel of Figure 4 shows the mean amount of Coc diet, as a percentage of total amount eaten, ingested by the observers in the experimental and control groups whose demonstrators had eaten either the Coc or the Cin diet. The right panel of the figure illustrates the mean percentage of the demonstrators' diet eaten (see Data Analysis of Experiment 2) by subjects in the control and experimental groups. As can be seen in Figure 4, observers in the control group exhibited a preference for their respective demonstrators' diets, whereas those in the experimental group exhibited an aversion to it (MannWhitney $U$ tests, see Figure 6 for $U$ and $p$ values).

The data of the present experiment indicate that $1 \mathrm{~h}$ after a rat ingests a diet, that rat emits traces of that diet sufficient to serve as a CS for observers in toxicosis-induced aversion learning.

\section{GENERAL DISCUSSION}

The results of the present series of studies extend our previous work on social transmission of information concerning distant diets (Galef, 1983; Galef, Kennett, \& Stein, 1985; Galef, Kennett, \& Wigmore, 1984; Galef $\&$ Wigmore, 1983) by demonstrating that the occurrence of delays between demonstrator ingestion of a food and interaction of demonstrator and observer does not block the ability of observers to identify their respective demonstrators' diets.

The finding in Experiments 2 and 3 that diet-identifying cues emitted by demonstrators for 1 to $2 \mathrm{~h}$ following diet ingestion are adequate conditional stimuli for aversion learning is of some additional interest. If demonstrator rats are themselves able to detect the residual cues their observers use as CSs in aversion learning, such cues might serve as a means for bridging moderate delays between taste experience and illness in poison-avoidance learning.
Although rats are clearly able to tolerate long delays between taste and toxicosis even in the absence of peripheral mediators (Revusky \& Garcia, 1970; Rozin, 1977), Experiments 2 and 3 provide evidence of the presence of peripheral cues that might supplement central mediation of taste-aversion learning over relatively brief long delays.

\section{REFERENCES}

BARKER, L. M. (1976). CS duration, amount, and concentration effects in conditioning taste aversions. Learning and Motivation, 7, 265-273.

ChitTy, D. (1954). The study of the brown rat and its control by poison. In D. Chitty (Ed.), The control of rats and mice (Vol. 1). Oxford: Clarendon Press.

GALEF, B. G., JR. (1983). Utilization by Norway rats ( $R$. norvegicus) of multiple messages concerning distant foods. Journal of Comparative Psychology, 97, 364-371.

Galef, B. G., Jr., Kennett, D. J., \& Stein, M. (1985). Demonstrator influence on observer diet preference: Effects of simple exposure and the presence of a demonstrator. Animal Learning \& Behavior, $13,25-30$

Galef, B. G., Jr., Kennett, D. J., \& Wigmore, S. W. (1984). Transfer of information concerning distant food in rats: A robust phenomenon. Animal Learning \& Behavior, 12, 292-296.

Galef, B. G., JR., \& Wigmore, S. W. (1983). Transfer of information concerning distant foods: A laboratory investigation of the 'information-centre' hypothesis. Animal Behaviour, 31, 748-758.

Galef, B. G., JR., Wigmore, S. W., \& Kennett, D. J. (1983). A failure to find socially mediated taste aversion learning in Norway rats ( $R$. norvegicus). Joumal of Comparative Psychology, 97, 358-363.

Hankins, W. G., Garcia, J., \& Rusiniak, K. W. (1973). Dissociation of odor and taste baitshyness. Behavioral Biology, 8, 407-419.

Posadas-Andrews, A., \& RoPer, T. J. (1983). Social transmission of food preferences in aduit rats. Animal Behaviour, 31, 265-271.

Revusky, S. H., \& GaRCIA, J. (1970). Learned associations over long delays. In G. H. Bower \& J. T. Spence (Eds.), The psychology of learning and motivation (Vol. 4). New York: Academic Press.

RoziN, P. (1977). The significance of learning mechanisms in food selection: Some biology, psychology, and sociology of science. In L. M. Baker, M, R. Best, \& M. Domjan (Eds.), Learning mechanisms in food selection. Waco: Baylor University Press.

STRUPP, B. J., \& LeVITSKY, D. A. (1984). Social transmission of food preference in adult hooded rats (Rattus norvegicus). Joumal of Comparative Psychology, 98, 257-266.

(Manuscript received July 10, 1984; revision accepted for publication January 11, 1985.) 